\title{
Adhesives for fixed orthodontic brackets (Review)
}

Mandall NA, Hickman J, Macfarlane TV, Mattick RCR, Millett DT, Worthington HV

Mandall NA, Hickman J, Macfarlane TV, Mattick RCR, Millett DT, Worthington HV. Adhesives for fixed orthodontic brackets.

Cochrane Database of Systematic Reviews 2018, Issue 4. Art. No.: CD002282.

DOI: 10.1002/14651858.CD002282.pub2.

www.cochranelibrary.com 
HEADER

ABSTRACT

PLAIN LANGUAGE SUMMARY

BACKGROUND

OBJECTIVES

METHODS

RESULTS

Figure 1.

DISCUSSION

AUTHORS' CONCLUSIONS

ACKNOWLEDGEMENTS

REFERENCES

CHARACTERISTICS OF STUDIES

ADDITIONAL TABLES

APPENDICES

WHAT'S NEW

HISTORY

CONTRIBUTIONS OF AUTHORS

DECLARATIONS OF INTEREST

SOURCES OF SUPPORT

NOTES

INDEX TERMS

\section{TABLE OF CONTENTS}

1

1

2

3

3

3

5

6

8

8

8

9

10

14

15

16

16

17

17

17

17

17 
[Intervention Review]

\section{Adhesives for fixed orthodontic brackets}

Nicky A Mandall ${ }^{1}$, Joy Hickman², Tatiana V Macfarlane ${ }^{3}$, Rye CR Mattick ${ }^{4}$, Declan T Millett ${ }^{5}$, Helen V Worthington 6

1Orthodontic Department, Tameside General Hospital, Ashton under Lyne, UK. 2Department of Orthodontics, Glan Clwyd Hospital, Rhyl, UK. ${ }^{3}$ School of Medicine and Dentistry, University of Aberdeen, Aberdeen, UK. ${ }^{4}$ Department of Orthodontics, Newcastle Dental Hospital, Newcastle upon Tyne, UK. ${ }^{5}$ Oral Health and Development, Cork University Dental School and Hospital, Cork, Ireland. ${ }^{6}$ Cochrane Oral Health, Division of Dentistry, School of Medical Sciences, Faculty of Biology, Medicine and Health, The University of Manchester, Manchester, UK

Contact address: Nicky A Mandall, Orthodontic Department, Tameside General Hospital, Fountain Street, Ashton under Lyne, Lancashire, OL6 9RW, UK. nicky.mandall@tgh.nhs.uk.

Editorial group: Cochrane Oral Health Group.

Publication status and date: Stable (no update expected for reasons given in 'What's new'), published in Issue 5, 2018.

Citation: Mandall NA, Hickman J, Macfarlane TV, Mattick RCR, Millett DT, Worthington HV. Adhesives for fixed orthodontic brackets. Cochrane Database of Systematic Reviews 2018, Issue 4. Art. No.: CD002282. DOI: 10.1002/14651858.CD002282.pub2.

Copyright ( 2018 The Cochrane Collaboration. Published by John Wiley \& Sons, Ltd.

\section{A B S T R A C T}

\section{Background}

Bonding of orthodontic brackets to teeth is important to enable effective and efficient treatment with fixed appliances. The problem is bracket failure during treatment which increases operator chairside time and lengthens treatment time. A prolonged treatment is likely to increase the oral health risks of orthodontic treatment with fixed appliances one of which is irreversible enamel decalcification. This is an update of the Cochrane Review first published in 2003. A new full search was conducted on 26 September 2017 but no new studies were identified. We have only updated the search methods section in this new version. The conclusions of this Cochrane Review remain the same.

\section{Objectives}

To evaluate the effects of different orthodontic adhesives for bonding.

\section{Search methods}

Cochrane Oral Health's Information Specialist searched the following databases: Cochrane Oral Health's Trials Register (to 26 September 2017), the Cochrane Central Register of Controlled Trials (CENTRAL; 2017, Issue 8) in the Cochrane Library (searched 26 September 2017), MEDLINE Ovid (1946 to 26 September 2017), and Embase Ovid (1980 to 26 September 2017). The US National Institutes of Health Ongoing Trials Register (ClinicalTrials.gov) and the World Health Organization International Clinical Trials Registry Platform were searched for ongoing trials. No restrictions were placed on the language or date of publication when searching the electronic databases.

\section{Selection criteria}

Trials were selected if they met the following criteria: randomised controlled trials (RCTs) and controlled clinical trials (CCTs) comparing two different adhesive groups. Participants were patients with fixed orthodontic appliances. The interventions were adhesives that bonded stainless steel brackets to all teeth except the molars. The primary outcome was debond or bracket failure.

\section{Data collection and analysis}

Data were recorded on decalcification as a secondary outcome, if present. Information regarding methods, participants, interventions, outcome measures and results were extracted in duplicate by pairs of review authors. Since the data were not presented in a form that was amenable to meta-analysis, the results of the review are presented in narrative form only. 


\section{Main results}

Three trials satisfied the inclusion criteria. A chemical cured composite was compared with a light cured composite (one trial), a conventional glass ionomer cement (one trial) and a polyacid-modified resin composite (compomer) (one trial). The quality of the trial reports was generally poor.

\section{Authors' conclusions}

There is no clear evidence on which to make a clinical decision of the type of orthodontic adhesive to use.

\section{PLAIN LANGUAGE SUMMARY}

\section{Adhesives for fixed orthodontic brackets}

\section{Background}

It is useful for a clinician to know the best adhesive for fixing orthodontic brackets, so they do not fail during treatment. Bracket failure increases the time spent in surgery for repairs and the overall treatment time. At present orthodontics can choose between four groups of adhesives which may be set with a chemical reaction or curing light. Some adhesives may prevent early decay around brackets because they contain fluoride.

\section{Study characteristics}

The evidence in this review, which was carried out together with Cochrane Oral Health, is up-to-date as of 26 September 2017 . We included three studies: a chemical cured composite was compared with a light cured composite (one trial), a conventional glass ionomer cement (one trial), and a polyacid-modified resin composite (compomer) (one trial). The quality of the trial reports was generally poor.

\section{Key results}

There is no clear evidence on which to make a clinical decision of the type of orthodontic adhesive to use. 


\section{B A C K G R O U N D}

Orthodontic treatment involves using fixed or removable appliances on teeth, mostly in early teenage children, to correct crooked teeth. In England and Wales between April 1999 and March 2000 , claims for orthodontic treatment were made by the General Dental Services (DPB 2000) at an approximate cost of GBP 57 million to the National Health Service.

The majority of orthodontic treatment is carried out in children aged 10 to 14 years and is primarily concerned with correcting severe crowding and rotations, buried teeth and very prominent teeth. In the UK, epidemiological data revealed that two thirds of 11 to 12 year old children had either a moderate or severe need for orthodontic treatment (Evans 1987; Holmes 1992). There is also a huge demand for treatment as shown by the current long length of waiting lists, with an average wait of 16 months in the British Dental Services (Russell 1999).

\section{Description of the intervention}

\section{Treatment with fixed orthodontic appliances}

It has been shown that the quality of fixed appliance treatment is much higher than with removable appliances (O'Brien 1993; Richmond 1993) and it is therefore the way that most orthodontists like to treat their patients.

\section{Adhesives for fixed orthodontic appliances}

The success of a fixed orthodontic appliance depends on the metal brackets being bonded to the teeth so that they do not fall off (debond) and protection against caries (decay) during treatment. There should be a low rate of failure. The need to replace brackets frequently, during a 2-year course of treatment, slows down the progress of treatment with a fixed appliance. It can also be costly in terms of clinical time, materials and time lost from education/work for the patient.

Orthodontic brackets are subjected to a large number of forces in the mouth resulting in a complex distribution of stresses within the adhesive and its junctions with the tooth surface and the bracket base (Sunna 1998).

Ideally the adhesive should be:

- strong enough to keep the brackets bonded to the teeth for the length of the treatment;

- not so strong that the tooth surface is damaged when the appliance is removed;

- easy to use clinically;

- protect against dental caries (decay);

- be available at a reasonable cost.

Adhesives currently available for bonding brackets to teeth are those with a resin/matrix composition, similar to 'white' filling materials (composites) and those supplied as a powder with liquid, or powder with water (glass ionomer cements). Composites have been modified in recent years to form polyacid-modified resin composites (compomers). Glass ionomers have been modified by adding a resin to form resin-modified glass ionomer cements. Composites and glass ionomer cements may be set by a chemical reaction within the adhesive (chemical curing) or this may be triggered by shining a blue light onto the adhesive (light curing).

\section{Why it is important to do this review}

The question which of these four groups of adhesives bond most reliably to teeth, as well as reducing or preventing dental caries (decay), remains to be answered.

This is an update of the Cochrane Review first published in 2003. A new full search was conducted on 26 September 2017 but no new studies were identified. We have only updated the search methods section in this new version. The conclusions of this Cochrane Review remain the same.

\section{O B J E C T IVES}

To evaluate the effects of orthodontic adhesives in terms of whether or how often the bracket comes off during treatment (binary or continuous variable).

\section{METHODS}

\section{Criteria for considering studies for this review Types of studies}

Only randomised controlled trials (RCTs) and controlled clinical trials (CCTs) (using quasi-methods of randomisation e.g. alternation) that compared adhesives to attach fixed orthodontic appliances to teeth were included in this review. The fixed appliance should be attached to most of the teeth in at least one jaw. The trials included should compare at least two different groups of adhesives.

\section{Types of participants}

Patients with fixed appliances attached to their teeth. Patients with cleft lip or palate or both or any other syndrome were excluded. Additionally patients involved in any type of surgery including surgical uncovering (exposure) of buried teeth, but not surgical extraction of teeth as part of the orthodontic treatment plan were excluded.

\section{Types of interventions}

Adhesives used to fix orthodontic appliances to teeth. The adhesives refer to those that attach the metal brackets to the front teeth and not the adhesives used to attach metal bands to the molar teeth.

Studies are excluded which:

- compared adhesives from the same group, that used the same curing mechanism

- used ceramic or plastic brackets

- used lingual appliances

- varied etching times

- did not follow the patients to the end of appliance treatment

- reported the data incorrectly or with insufficient information so that it could not be used in the review, unless the authors could supply appropriate data.

\section{Comparison of adhesives}

A comparison was made between light cured and chemical cured adhesives for the following groups.

- Conventional composite (will be referred to as 'composite'). 
- Conventional glass ionomer cement (GIC).

- Polyacid-modified composites (compomers).

- Resin-modified glass ionomer cement.

Comparisons were made between the above groups of adhesives and within groups, between chemical and light cured adhesives.

\section{Types of outcome measures}

- Primary outcomes: binary data on the failure of each adhesive (whether metal bracket stays stuck to the tooth or not) were recorded. It was planned that where these data were not available annualised failure rate of adhesives, i.e. the rate at which the metal brackets fall off the teeth during treatment, would be noted if possible, however, no trial reports gave us this information.

- Secondary outcomes: binary data on the presence or absence of decay (decalcification) associated with or around the brackets were recorded if available.

\section{Search methods for identification of studies}

\section{Electronic searches}

Cochrane Oral Health's Information Specialist conducted systematic searches in the following databases for randomised controlled trials and controlled clinical trials without language or publication status restrictions:

- Cochrane Oral Health's Trials Register (searched 26 September 2017) (Appendix 1);

- Cochrane Central Register of Controlled Trials (CENTRAL; 2017, Issue 8) in the Cochrane Library (searched 26 September 2017) (Appendix 2);

- MEDLINE Ovid (1946 to 26 September 2017) (Appendix 3);

- Embase Ovid (1980 to 26 September 2017) (Appendix 4).

Subject strategies were modelled on the search strategy designed for MEDLINE Ovid. Where appropriate, they were combined with subject strategy adaptations of the highly sensitive search strategy designed by Cochrane for identifying randomised controlled trials and controlled clinical trials as described in the Cochrane Handbook for Systematic Reviews of Interventions Chapter 6 (Lefebvre 2011).

\section{Searching other resources}

The following trial registries were searched for ongoing studies (see Appendix 5 for details of the search strategy):

- US National Institutes of Health Ongoing Trials Register ClinicalTrials.gov (clinicaltrials.gov; searched 26 September 2017);

- World Health Organization International Clinical Trials Registry Platform (apps.who.int/trialsearch; searched 26 September 2017).

Handsearching of the following journals was carried out by the review authors:

- European Journal of Orthodontics (1979 to 2002);

- American Journal of Orthodontics and Dentofacial Orthopedics (1970 to 2002);

- British Journal of Orthodontics (became Journal of Orthodontics in 2000) (1973 to 2002);
- Angle Orthodontist (1978 to 2002).

All first authors of trials were contacted in an attempt to identify any unpublished studies and clarify information about published trials (including missing data, method of randomisation, blinding and withdrawals). The references quoted in the included studies were screened for any further trials. Manufacturers of adhesives were contacted to confirm the adhesive type.

We searched the reference lists of included studies and relevant systematic reviews for further studies.

We did not perform a separate search for adverse effects of interventions used, we considered adverse effects described in included studies only.

\section{Data collection and analysis}

All authors were involved in handsearching. Two authors independently screened titles and abstracts from the electronic searches and identified eligible studies, carried out the quality assessment of included studies and extracted the data in duplicate without blinding to the authors, or adhesives used. A third review author, Helen Worthington (HW), assisted with data analysis and where doubt existed about the inclusion of trials.

The date that the study was conducted, the year of publication, treatments, outcomes, sample size and age of subjects were recorded. The number recruited and details of withdrawals by study group were recorded.

The primary outcome measures were adhesive failure and decalcification. Other reported outcomes were recorded for descriptive purposes.

Studies eligible for inclusion were identified. The results of the randomised controlled trials (RCTs) and controlled clinical trials (CCTs) were analysed using RevMan and reported according to Cochrane Collaboration criteria.

\section{Quality assessment}

The quality of each paper included was assessed, independently, by two people (Nicky Mandall (NM) and Rye Mattick (CRM); Declan Millett (DTM) and Joy Hickman (JH2)). In the case of any discrepancies, the paper was assessed by a third person. The quality assessment included concealment of randomisation, sample size calculation, inclusion and exclusion criteria, completeness of follow up, management of study drop outs and examiner blinding, whether control and treatment groups were comparable at entry and whether groups are treated identically other than the named intervention.

\section{Assessment of the appropriateness of the statistical analysis}

Two authors, who are senior statisticians (Helen Worthington (HW), Tatiana Macfarlane (TM)), assessed all the eligible studies for the appropriateness of their statistical analysis. The results of the assessments were compared during a consensus meeting. The statistical analysis was considered inappropriate if.

- A split-mouth design where an inappropriate statistical test was used, that did not take the clustering of the teeth or 'pairing' into account. 
- All failures were included without taking into account multiple failures on the same tooth.

There were insufficient studies to conduct a planned sensitivity analysis to see how the quality affected any treatment effects.

\section{Data synthesis}

The following data synthesis was planned however there were insufficient trials to conduct a meta-analysis or any of the other procedures below.

1. To assess heterogeneity by inspection of a graphical display of the estimated treatment effects from the trials along with their $95 \%$ confidence intervals and by Cochran's test for homogeneity undertaken before each meta-analysis.

2. Follow the Cochrane Statistical Methods Group guidelines, calculating summary risk ratio values along with $95 \%$ confidence intervals using a random-effects model. The number needed to treat (NNT) was to be calculated to prevent one extra bracket failing, as appropriate.

3. Undertake a sensitivity analysis as follows: excluding unpublished studies, excluding studies of low quality; excluding one or more large studies to assess how much they dominate the results.

4. To investigate publication and other biases by drawing a funnel plot (plots of effect estimates versus the inverse of their standard errors). Asymmetry of the funnel plot may indicate publication bias and other biases related to sample size, though it may also represent a true relationship between trial size and effect size. It was planned to conduct a formal investigation of the degree of asymmetry using the method proposed by Egger et al (Egger 1997).

5. No subgroup analyses were planned.

Where the statistical analysis was appropriate, the data tended to be presented without standard deviations, or with statistical techniques which were not amenable to meta-analysis. Therefore, the results of the trials included in the review will be presented in narrative form only.

\section{RESULT S}

\section{Description of studies}

See Characteristics of included studies table.
See Characteristics of excluded studies table.

\section{Characteristics of the trial settings and investigators}

Of the 25 eligible studies, 22 were excluded for the following reasons:

- in seven trials the comparisons were of two chemically cured composites (Ash 1996; Banks 1997; Chung 2000; Mitchell 1992; Turner 1993; Underwood 1989; Zacchrisson 1978)

- in one trial the comparison was of two-light cured composites (Sonis 1989)

- in ten trials the statistical analysis was inappropriate (eight trials: Fricker 1992; Fricker 1994; Fricker 1998; Lovius 1987; Miguel 1995; Miller 1996; Sunna 1998; Trimpaneers 1996) or unclear (two trials: Cacciafesta 1999; Shamma 1999) and the data presented were not in a form for correct analysis

- in three trials the patients were not followed through to the end of treatment (DeSaeytijd 1994; Galindo 1998; Gaworski 1999)

- in the split-mouth studies, it is important that the data are analysed taking the clustering or pairing within the patient into account. Six trials failed to do this (Fricker 1992; Fricker 1994; Fricker 1998; Miguel 1995; Sunna 1998; Trimpaneers 1996) and the analysis was unclear in a further split-mouth study (Cacciafesta 1999). Two full mouth studies analysed teeth as though they were independent (ignoring clustering within patients (Miller 1996; Shamma 1999)). A further study conducted a survival analysis including second time failures (Lovius 1987).

Letters were written to the authors of the 25 eligible studies and eleven replies were received clarifying that they knew of no unpublished studies. All the manufacturers of adhesives contacted responded and confirmed the adhesive group.

Three trials were identified which fulfilled the inclusion criteria (Millett 2000; Norevall 1996; O'Brien 1989). Two were randomised controlled trials (Norevall 1996; O'Brien 1989) and one was a controlled clinical trial (Millett 2000), and all were carried out in a hospital setting. The countries where the trials were carried out were in the UK (two trials: Millett 2000; O'Brien 1989) and Sweden (one trial: Norevall 1996). All three trials used a split-mouth design and one trial reported decalcification as a secondary outcome.

There are no other studies waiting assessment. See Figure 1. 
Figure 1. Study flow diagram.

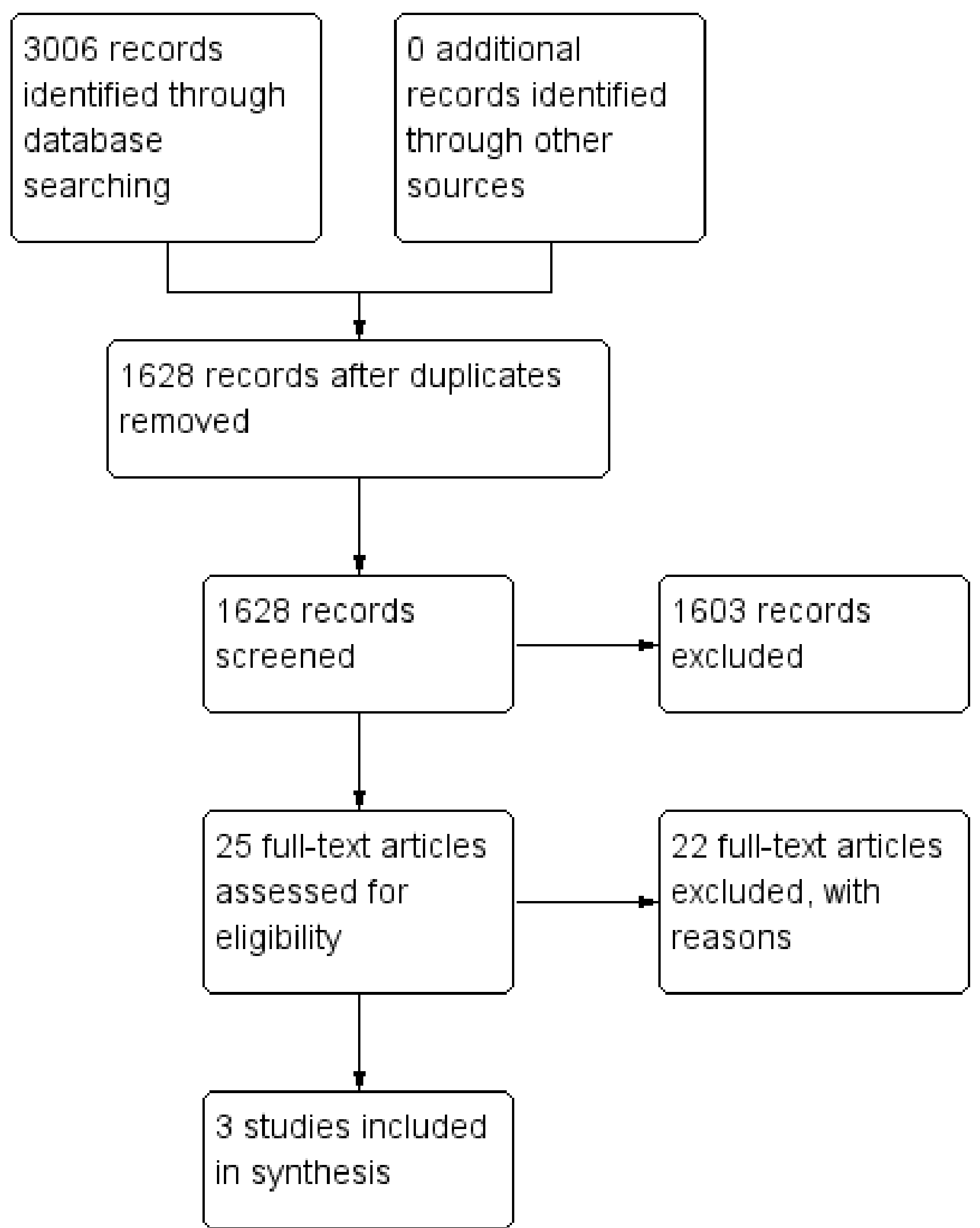




\section{Characteristics of the participants}

The three trials recruited between 45 and 60 patients who were between 10 years 8 months and 29 years of age.

\section{Characteristics of the interventions}

In one trial, decalcification was reported as a secondary outcome (Millett 2000). Thus, the trials were divided for comparison of orthodontic adhesives as follows.

- Chemical cured composite versus light cured composite (O'Brien 1989).

- Chemical cured composite versus conventional glass ionomer cement (Norevall 1996).

- Chemical cured composite versus compomer (Millett 2000).

No included studies involved a comparison with resin-modified glass ionomer cement.

\section{Characteristics of outcome measurements}

All three included trials reported adhesive failure as the number of teeth with debonded brackets and the percentage debond per group. Two studies (Norevall 1996; O'Brien 1989) reported debonds for the same adhesive but two different bracket bases: a mesh foil base compared with either a Dynalok cut groove base or GAC Microloc. One study (Millett 2000) reported decalcification as a secondary outcome. Although Norevall 1996 compared a chemical cured composite with a conventional glass ionomer cement decalcification was not recorded. For the third study (O'Brien 1989) decalcification was not an appropriate secondary outcome because two composite resins were compared, which do not have any scope to prevent decalcification.

\section{Risk of bias in included studies}

\section{Selection bias}

The two randomised controlled trials (RCTs) were assessed for allocation concealment and this was unclear in both trials. The papers did not report how or whether they concealed the treatment allocation until just before the bond-up procedure. The third study used alternation, therefore allocation concealment was considered as at high risk of bias.

\section{Detection bias}

The outcome of interest was debond which is a very definite outcome (cannot be half debonded). It has been assumed that the operator treating the patients recorded the debond and if this was the case it is unlikely that the operator was blinded to the adhesive allocation as the adhesives look different. Arguably, lack of reported blinding is less likely to be subjected to bias in view of the definitive primary outcome (debond). The outcome of decalcification is more prone to examiner bias unless the outcome assessor is blinded. The controlled clinical trial (CCT) where this was an outcome (Millett 2000) reported that examiner assessment of decalcification was blinded to the intervention. This is more easy to do because decalcification was measured after debonding at the end of treatment.

\section{Performance bias}

Groups treated identically apart from named intervention: as all the studies were designed as split-mouth trials, it is unlikely that different parts of the mouth were treated differently, although Millett 2000 reported identical treatment of patients, for example, bonding preparation, initial archwire, written instructions and the use of fluoride mouthwash.

Blinding of the clinician to the treatment allocation would not be feasible in all studies, since the operator could not be blinded to specific clinical techniques, e.g. light curing of the adhesive versus chemical cure. Another clinician may be able to bond the appliance, the operator taking over the treatment and recording the outcome would then be blinded to the adhesive used. Blinding of the patient could be achieved, but would not necessarily be relevant, and was not discussed in any of the studies.

\section{Attrition bias}

It was unclear from the trial reports for all three trials whether there were any withdrawals or not. Two authors responded to correspondence. There were two dropouts in one study, but it was unclear which group (Millett 2000) and no dropouts or withdrawals in another study (Norevall 1996).

It was assumed that the data analysis was carried out on all the participants registered in the trials.

\section{Other bias}

- Sample size calculation: no trials reported this.

- Definition of inclusion/exclusion criteria: in all trials this was unclear or poorly defined.

- Completeness of follow-up: since no withdrawals were reported it appeared that greater than $80 \%$ follow-up was achieved for all included trials.

- Control and treatment groups comparable at entry: all included trials were a split-mouth design, this meant that there should be good comparability of adhesive groups within each patient. This factor was unlikely to have confounded the studies.

- The experience of the operator was not recorded and this could affect bonding performance. No discussion was made relating to the improved operator bonding performance as the clinician became more familiar with the different materials throughout the trial. There may be variability (and therefore performance bias) between different batches of the same material.

\section{Effects of interventions}

\section{Chemical cured (CC) composite versus light cured (LC) composite}

Additional Table 1 summarises the proportion of bracket failures for a CC and LC composite with two different bracket bases (O'Brien 1989). The paper reported the results of applying a Mantel-Haenszel $\mathrm{Chi}^{2}$ test which found no statistically significant differences in bracket failure rates between the CC and LC composites studied. The adhesive names where not reported as they were experimental.

\section{CC composite versus standard chemical cured glass ionomer cement (CC GIC)}

The one trial article for this adhesive comparison reported the results of paired t-tests comparing different sides of the mouth. No standard deviations were presented, so we were unable to reproduce the data. The results suggested that standard CC GIC exhibited statistically significantly higher proportions of failed 
bracket compared with $\mathrm{CC}$ composite $(\mathrm{P}<0.001)$ (Additional Table 2) (Norevall 1996). It was surprising that decalcification rates were not reported as a secondary outcome, as clinically it is suggested that GIC is protective against decalcification.

\section{CC composite versus compomer}

There is only one trial in this composite group (Millett 2000). As this was a split-mouth study the odds ratio taking into account the pairing was calculated as 0.86 (95\% confidence interval $(\mathrm{Cl}): 0.24$ to 2.98 ), with no statistically significant differences between Dyract Ortho (compomer) and Right-On for bracket failure rates. However the paper reported that the compomer offered better protection against decalcification when compared by a sign test $(P=0.0075)$. (Additional Table 3).

\section{DISCUSSION}

This systematic review of the literature, has highlighted that there are many clinical trials of orthodontic adhesives, notably comparing chemical cured (CC) composite with either light cured (LC) composite or conventional chemical cured glass ionomer cement (CC GIC), but few could be included due to the inappropriate statistical analysis of the trials. Fewer studies have included materials such as compomers or resin-modified light cured glass ionomer cement (LC GIC).

It was very disappointing that so many studies could not be included in the review because of inappropriate statistical analysis. In addition, a formal meta-analysis could not be carried out on the data because although per cent bracket failure rates were reported, the means and standard deviations for each group, were not always published. Split-mouth studies were frequently analysed by $\mathrm{Chi}^{2}$ tests failing to take the pairing of the data within the patients' mouths into account. Other studies were excluded as teeth were treated independently in the analysis, ignoring the clustering of teeth within the mouth. Another issue is the inappropriateness of conducting survival analysis using second time failures.

\section{Qualitative comparison of orthodontic adhesives}

(i) CC composite versus LC composite

It was notable that many composite adhesives from different manufacturers have been studied. However, when stringent exclusion criteria and quality analysis are used, it proved impossible to make generalisations about whether a light cured or chemical cured composite should be used. This is disappointing, since the review has highlighted a lack of scientific evidence to either support or refute the advantage of light cured systems.

(ii) CC composite versus CC conventional GIC

The use of a composite resin adhesive over conventional glass ionomer cement, at their present stage of development, is supported. However, it was surprising that decalcification was not investigated by this comparative study.

\section{(iii) CC composite versus compomer}

The only trial to carry out this comparison found no evidence to suggest that a compomer did not have a comparable bracket failure rate to a CC composite. This suggests that the role of compomers for future orthodontic bonding may merit further investigation, particularly in view of their possible potential for reducing decalcification.

\section{Reporting quality}

The high rates of patient follow-up suggest that it is possible to minimise 'attrition bias' in trials comparing orthodontic adhesives. However, for other quality indicators the reporting quality was low. In particular for describing characteristics of patient withdrawals or dropouts and for attempts to make the studies either single blind or double blind.

It would be possible to blind both the patient and the operator if both adhesives being compared were either light or chemical cured and had the same mixing requirements. Patients could be blinded, if adhesives with different polymerisation mechanisms were used. It is also possible to blind the operator by having a different clinician placing the brackets.

\section{AUTHORS' CONCLUSIONS}

\section{Implications for practice}

It is not possible to draw anything other than tentative conclusions from this systematic review of orthodontic adhesives, primarily because of the weakness in the design and reporting of existing trials. Therefore, at present, there is no clear evidence on which to make a clinical decision of the type of orthodontic adhesive to use.

\section{Implications for research}

There are a number of suggestions that may be made as a result of this review, the majority of which are based on the quality of reporting of clinical trials. Researchers might consider.

- Undertaking randomised controlled trials involving resinmodified light cured glass ionomer cement (LC GIC) or compomers.

- Calculating a sample size a priori.

- Stating clear inclusion and exclusion criteria.

- Describing patient withdrawal and drop outs and modifying the statistical analysis if appropriate.

- Assessing for occlusal interferences that may affect bond failure.

- Attempting to make studies single blind (patient) or double blind (patient and operator) if feasible.

- Treating all patients in the same way apart from the intervention.

- Measuring decalcification as a secondary outcome where appropriate.

- Using appropriate statistical analysis and involving a statistician in the design and analysis of the trial. In split-mouth studies, it is important that the data are analysed taking the clustering or pairing within the patient into account.

\section{ACKN OWLEDGEMENTS}

Dr Jayne Harrison for her help and support in writing the method of the review.

Miss Anne-Marie Glenny for her support.

Miss Anne Littlewood and Mrs Luisa Fernandez Mauleffinch in their role at Cochrane Oral Health.

The review authors would also like to thank the following trialists who responded to our request for additional information about their studies: C De Saeytijd, John Fricker, Matthew Gaworski, James Miller, Declan Millet, Kevin O'Brien, Imad Shamma, S Sunna, LM Trimpaneer, Bjorn Zachrisson. 


\section{REFERE N CES}

\section{References to studies included in this review}

Millett 2000 \{published data only\}

Millett DT, McCluskey LA, McAuley F, Creanor SL, Newell J, Love J. A comparative clinical trial of a compomer and a resin adhesive for orthodontic bonding. Angle Orthodontist 2000;70:233-40.

\section{Norevall 1996 \{published data only\}}

Norevall LI, Marcusson A, Persson M. A clinical evaluation of a glass ionomer cement as an orthodontic bonding adhesive compared with an acrylic resin. European Journal of Orthodontics 1996;18:373-84.

O'Brien 1989 \{published data only\}

O'Brien KD, Read MJF, Sandison RJ, Roberts CT. A visible lightactivated direct-bonding material: An in vivo comparative study. American Journal of Orthodontics and Dentofacial Orthopedics 1989;95:348-51.

\section{References to studies excluded from this review}

Ash 1996 \{published data only\}

Ash S, Hay N. Adhesive pre-coated brackets, a comparative clinical study. British Journal of Orthodontics 1996;23:325-9.

\section{Banks 1997 \{published data only\}}

Banks PA, Burn A, O'Brien KD. A clinical evaluation of the effectiveness of including fluoride into an orthodontic bonding adhesive. European Journal of Orthodontics 1997;19:391-5.

\section{Cacciafesta 1999 \{published data only\}}

Cacciafesta V, Bosch C, Melsen B. Clinical comparison between a resin-reinforced self-cured glass ionomer cement and a composite resin for direct bonding of orthodontic brackets. Part 2: bonding on dry enamel and on enamel soaked with saliva. Clinical Orthodontics and Research 1999:2:186-93.

Chung 2000 \{published data only\}

Chung $\mathrm{CH}$, Piatti A. Clinical comparison of the bond failure rates between fluoride-releasing and non-fluoride releasing composite resins. Journal of Clinical Orthodontics 2000;XXXIV:409-12.

\section{DeSaeytijd 1994 \{published data only\}}

Saeytijd C De, Carels CEL, Lesaffre E. An evaluation of a lightcuring composite for bracket placement. European Journal of Orthodontics 1994;16:541-5.

\section{Fricker 1992 \{published data only\}}

Fricker JP. A 12-month clinical evaluation of a glass polyalkenoate cement for the direct bonding of orthodontic brackets. American Journal of Orthodontics and Dentofacial Orthopedics 1992;101:381-4.

\section{Fricker 1994 \{published data only\}}

Fricker JP. A 12-month clinical evaluation of a light- activated glass polyalkenoate (ionomer) cement for the direct bonding of orthodontic brackets. American Journal of Orthodontics and Dentofacial Orthopedics 1994;105:502-5.

Fricker 1998 \{published data only\}

Fricker JP. A new self-curing resin-modified glass-ionomer cement for the direct bonding of orthodontic brackets in vivo. American Journal of Orthodontics and Dentofacial Orthopedics 1998;113:384-6.

\section{Galindo 1998 \{published data only\}}

Galindo HRA, Sadowsky PL, Vlachos C, Jacobson A, Wallace D. An in vivo comparison between a visible light-cured bonding system and a chemically cured bonding system. American Journal of Orthodontics and Dentofacial Orthopedics 1998;113:271-5.

\section{Gaworski 1999 \{published data only\}}

Gaworski M, Borislow AJ, Braitman LE. Decalcification and bond failure: A comparison of a glass ionomer and a composite resin bonding system in vivo. American Journal of Orthodontics and Dentofacial Orthopedics 1999;116:518-21.

Hons 1994 \{published data only\}

Hons I. A comparative study of four orthodontic bonding systems. A comparative study of treatment effects of two Herbst appliances (Abstract). European Journal of Orthodontics 1994;16(5):456

Lovius 1987 \{published data only\}

Lovius BBJ, Pender N, Hewage S, O'Dowling I, Tomkins A. A clinical trial of a light activated bonding material over an 18 month period. British Journal of Orthodontics 1987;14:11-20.

Miguel 1995 \{published data only\}

Miguel JAM, Almeida MA, Chevitarese O. Clinical comparison between a glass ionomer cement and a composite for direct bonding of orthodontic brackets. American Journal of Orthodontics and Dentofacial Orthopedics 1995;107:484-7.

Miller 1996 \{published data only\}

Miller JR, Arbuckle G, Baldwin J, Phillips RW. A three-year clinical trial using a glass ionomer cement for the bonding of orthodontic brackets. Angle Orthodontist 1996;66:309-12.

Mitchell 1992 \{published data only\}

Mitchell L. An investigation into the effect of a fluoride releasing adhesive on the prevalence of enamel surface changes associated with directly bonded orthodontic attachments. British Journal of Orthodontics 1992;19:207-14.

Shamma 1999 \{published data only\}

Shamma I, Ngan P, Kim H, Kao E, Gladwin M, Gunel E, et al. Comparison of bracket debonding force between two conventional resin adhesives and a resin-reinforced glass ionomer cement: $A n$ in vitro and in vivo study. Angle Orthodontist 1999;69:463-9. 
Sonis 1989 \{published data only\}

Sonis AL, Snell W. An evaluation of a fluoride-releasing, visible light-activated bonding system for orthodontic bracket placement. American Journal of Orthodontics and Dentofacial Orthopedics 1989;95:306-11.

Sunna 1998 \{published data only\}

Sunna S, Rock WP. Clinical performance of orthodontic brackets and adhesive systems: A randomised clinical trial. British Journal of Orthodontics 1998;25:283-7.

\section{Trimpaneers 1996 \{published data only\}}

Trimpaneers LM, Dermaut LR. A clinical trial comparing the failure rates of two orthodontic bonding systems. American Journal of Orthodontics and Dentofacial Orthopedics 1996;110:547-50.

\section{Turner 1993 \{published data only\}}

Turner PJ. The clinical evaluation of a fluoride containing orthodontic bonding material. British Journal of Orthodontics 1993;20:307-13.

\section{Underwood 1989 \{published data only\}}

Underwood ML, Rawls HR, Zimmerman BF. Clinical evaluation of a fluoride-exchanging resin as an orthodontic adhesive. American Journal of Orthodontics and Dentofacial Orthopedics 1989;96:93-9.

\section{Zacchrisson 1978 \{published data only\}}

Zacchrisson BU, Brobakken BO. Clinical comparison of direct versus indirect bonding with different bracket types and adhesives. American Journal of Orthodontics and Dentofacial Orthopedics 1978;74:62-78.

\section{Additional references}

\section{DPB 2000}

Dental Practice Board, Statistical Department, Compton Place Road, Eastbourne, East Sussex, UK. (Correspondence) 1998.

\section{CHARACTERISTICS OF STUDIES}

Characteristics of included studies [ordered by study ID]

\section{Egger 1997}

Egger M, Davey Smith G, Scheider M, Minder CE. Bias in meta-analysis detected by a simple, graphical test. $B M J$ 1997;315:629-34

\section{Evans 1987}

Evans R, Shaw WC. Preliminary evaluation of an illustrated scale for rating dental attractiveness. European Journal of Orthodontics 1987;9:314-8.

\section{Holmes 1992}

Holmes A. The prevalence of orthodontic treatment need. British Journal of Orthodontics 1992;19:177-82.

\section{Lefebvre 2011}

Lefebvre C, Manheimer E, Glanville J. Chapter 6: Searching for studies. In: Higgins JP, Green S, editor(s). Cochrane Handbook for Systematic Reviews of Interventions Version 5.1.0 (updated March 2011). The Cochrane Collaboration, 2011. Available from handbook.cochrane.org.

\section{O'Brien 1993}

O'Brien KD, Shaw WC, Roberts CT. The use of occlusal indices in assessing the provision of orthodontic treatment by the hospital service of England and Wales. British Dental Journal 1993;20:25-35.

\section{Richmond 1993}

Richmond S, Shaw WC, Stephens CD, Webb WG, Roberts CT, Andrews M. Orthodontics in the General Dental Service of England and Wales. British Dental Journal 1993;174:315-29.

\section{Russell 1999}

Russell JI, Pearson AI, Bowden DEJ, Wright J, O'Brien KD. The Consultant Orthodontic Service - 1998 Survey. British Dental Journal 1999;187:149-53.

\section{References to other published versions of this review Mandall 2003}

Mandall NA, Hickman J, Macfarlane TV, Mattick RCR, Millett DT, Worthington HV. Adhesives for fixed orthodontic brackets. Cochrane Database of Systematic Reviews 2003, Issue 2. [DOI: 10.1002/14651858.CD002282]

Millett 2000

Methods Controlled clinical trial conducted as a hospital-based study in the UK. Split-mouth design. Blinding of treatment allocation unclear. Withdrawals not mentioned. Analysis appears to be based on all recruited cases.

Participants $\quad n=45$ patients. Age range 13.7 to 15.5 years, consecutively approached to take part in trial.

Interventions 
Millett 2000 (Continued)

2. light cured compomer (Dyract Ortho).

$\begin{array}{ll}\text { Outcomes } & \text { 1. Bond failure. } \\ \text { 2. Decalcification of upper and lower incisors and canines. }\end{array}$

Notes

Alternate randomisation method used to allocate patients. Inclusion/exclusion criteria unclear. Groups treated identically apart from named intervention. Statistics: paired log rank tests and Cox proportional hazards model. Data not amenable for MetaView.

\section{Risk of bias}

\begin{tabular}{lll}
\hline Bias & Authors' judgement & Support for judgement \\
\hline $\begin{array}{l}\text { Allocation concealment } \\
\text { (selection bias) }\end{array}$ & High risk & Study used alternation. \\
\hline
\end{tabular}

\section{Norevall 1996}

\begin{tabular}{ll}
\hline Methods & Randomised controlled trial conducted as a hospital-based study in Sweden. Split-mouth design. \\
& Blinding of treatment allocation unclear. Withdrawals not mentioned. Analysis appears to be based on \\
& all recruited cases.
\end{tabular}

\begin{tabular}{|c|c|c|}
\hline Participants & \multicolumn{2}{|c|}{$\begin{array}{l}\mathrm{n}=60 \text { patients. Age range } 10 \text { years } 8 \text { months to } 19 \text { years } 1 \text { month, consecutively approached to take } \\
\text { part in trial. }\end{array}$} \\
\hline Interventions & \multicolumn{2}{|c|}{$\begin{array}{l}\text { 2 groups compared: } \\
\text { 1. conventional GIC (Aquacem) } \\
\text { 2. chemical cured composite (Unite). } \\
\text { Also used } 2 \text { bracket bases Dyna loc (grooved base) and Unitwin (mesh base). }\end{array}$} \\
\hline Outcomes & \multicolumn{2}{|c|}{$\begin{array}{l}\text { 1. Bond failure for long and short treatment. } \\
\text { 2. Ahesive remnant index. } \\
\text { 3. Clean-up time at debond. }\end{array}$} \\
\hline Notes & \multicolumn{2}{|c|}{$\begin{array}{l}\text { Inclusion/exclusion criteria unclear. Unclear if groups treated identically apart from named interven- } \\
\text { tion. Statistics: t-tests calculated on patient basis but no standard deviations reported so cannot use } \\
\text { data. }\end{array}$} \\
\hline \multicolumn{3}{|l|}{ Risk of bias } \\
\hline Bias & Authors' judgement & Support for judgement \\
\hline $\begin{array}{l}\text { Allocation concealment } \\
\text { (selection bias) }\end{array}$ & Unclear risk & $\begin{array}{l}\text { Paper did not report how or whether they concealed the treatment allocation } \\
\text { until just before the bond-up procedure. }\end{array}$ \\
\hline
\end{tabular}

\section{O'Brien 1989}

\begin{tabular}{ll}
\hline Methods & $\begin{array}{l}\text { Randomised controlled trial conducted as a hospital-based study in the UK. Split-mouth design. Blind- } \\
\text { ing of treatment allocation unclear. Withdrawals not mentioned. Analysis appears to be based on all re- } \\
\text { cruited cases. }\end{array}$ \\
\hline Participants & $\mathrm{n}=52$ patients. Age range 13 to 29 years. 24 patients had two arch fixed and 22 had upper arch fixed on- \\
ly.
\end{tabular}


O'Brien 1989 (Continued)

\begin{tabular}{ll} 
Interventions & 2 groups compared: \\
1. chemical cured composite (unnamed) & 2. light cured compomer (unnamed). \\
& Also used 2 bracket bases Mesh foil and Micro loc. \\
\hline Outcomes & $\begin{array}{l}\text { 1. Bond failure. } \\
\text { 2. Number of patients with } 0,1,2,3 \text { bond failures. } \\
\text { 3. Bond failure by tooth type. }\end{array}$
\end{tabular}

Notes

Inclusion/exclusion criteria unclear. Unclear if groups treated identically apart from named intervention. Statistics: Mantel- Haenszel $\mathrm{Chi}^{2}$ but no standard deviations reported so unable to use data.

\section{Risk of bias}

\begin{tabular}{lll}
\hline Bias & Authors' judgement & Support for judgement \\
\hline $\begin{array}{l}\text { Allocation concealment } \\
\text { (selection bias) }\end{array}$ & Unclear risk & $\begin{array}{l}\text { Paper did not report how or whether they concealed the treatment allocation } \\
\text { until just before the bond-up procedure }\end{array}$ \\
\hline
\end{tabular}

\section{Characteristics of excluded studies [ordered by study ID]}

\begin{tabular}{ll}
\hline Study & Reason for exclusion \\
\hline Ash 1996 & $\begin{array}{l}\text { Comparison of } 2 \text { chemically cured composites (APC and Unite) ( } \mathrm{n}=38 \text { patients). } \\
\text { Bracket failures in first } 3 \text { months of treatment. RCT. }\end{array}$ \\
\hline Banks 1997 & $\begin{array}{l}\text { Comparison of } 2 \text { chemical cured composites (Rely-a-bond with fluoride and without fluoride) ( } \mathrm{n}= \\
\text { Bo patients). } \\
\text { Bond failure and decalcification reported. RCT. Patients followed to the end of active treatment. }\end{array}$ \\
\hline $\begin{array}{l}\text { Unable to use data. Statistical analysis unclear used paired t-test. } \\
\text { Compared chemical cured composite (system IT) and chemical cured glass ionomer cement (Fuji } \\
\text { ortho) ( } \mathrm{n}=38 \text { patients). Bond failures reported. CCT: randomly "alternated" adhesive allocation in } \\
\text { split-mouth design. }\end{array}$
\end{tabular}

Chung $2000 \quad$ Comparison of 2 chemically cured composites.

Compared fluoride releasing and non-fluoride releasing composite (Phase II) ( $n=23$ patients). Bond failure reported.

\begin{tabular}{ll}
\hline DeSaeytijd 1994 & Patients not followed to end of study. \\
& Compared chemical cured composite (Concise) with light cured composite (Heliosit) ( $\mathrm{n}=37$ pa- \\
tients). Bond failure, bond failure/tooth site reported. RCT.
\end{tabular}

Fricker 1992

Unable to use data. Statistical analysis inappropriate: $\mathrm{Chi}^{2}$ analysis and number of failures by tooth rather than on patient basis.

Compared chemical cured composite (system 1+) and light activated GIC (Fuji I) ( $n=10$ patients). Bond failure reported. CCT.

\begin{tabular}{ll}
\hline Fricker 1994 & $\begin{array}{l}\text { Unable to use data. Statistical analysis inappropriate: } \text { Chi2 }^{2} \text { analysis and number of failures by tooth } \\
\text { rather than on patient basis. } \\
\text { Compared chemical cured composite (system 1+) and light activated GIC (Fuji II LC) ( } \mathrm{n}=10 \mathrm{pa}- \\
\text { tients). Bond failure reported. CCT. }\end{array}$ \\
\hline Fricker 1998 & $\begin{array}{l}\text { Unable to use data. Statistical analysis inappropriate: } \mathrm{Chi}^{2} \text { analysis and number of failures by tooth } \\
\text { rather than on patient basis. }\end{array}$
\end{tabular}




\begin{tabular}{ll}
\hline Study & Reason for exclusion \\
\hline $\begin{array}{l}\text { Compared chemical cured composite (system 1+) and light activated GIC (Fuji Ortho } 1) \text { (n = 10 pa- } \\
\text { tients). Bond failure reported. CCT. }\end{array}$
\end{tabular}

\begin{tabular}{ll}
\hline Galindo 1998 & Patients not followed to the end of treatment. \\
& Compared chemical cured composite (system I+) and a light cured composite (sequence) ( $=32$ \\
consecutive patients). Bond failure reported. $\mathrm{RCT}$.
\end{tabular}

Gaworski $1999 \quad$ Patients not followed to the end of treatment.

Compared light cured composite with fluoride (Reliance light bond) and light cured aic (Fuji OrthoLC) ( $n=16$ consecutive patients). Bond failure and decalcification reported. CCT.

\begin{tabular}{ll}
\hline Hons 1994 & Abstract, insufficient information to assess or use data. \\
\hline Lovius 1987 & $\begin{array}{l}\text { Unable to use data. Unclear statistical analysis. Appears to have conducted on a bracket (not pa- } \\
\text { tient) basis. No standard deviations quoted for survival analysis so unable to use data in review. } \\
\text { Compared chemical cured composite (Right on) with light cured composite (Heliosit) ( } \mathrm{n}=122 \mathrm{pa}- \\
\text { tients). Bond failure reported. RCT. }\end{array}$ \\
\hline
\end{tabular}
Miguel $1995 \quad$ Unable to use data. Statistical analysis inappropriate: Chi $^{2}$ test number of failures on a tooth rather than patient basis.
Compared chemical cured composite (Concise) with chemical cured GIC (Ketac-cem) ( $n=16$ pa- tients). Bond failure and decalcification reported. CCT.

Miller 1996 Unable to use data. Statistical analysis inappropriate. Each tooth treated individually in survival curve (Kaplan-Meier analysis).

Compared chemical cured composite (Rely-a-bond) with chemical cured GIC (Ketac-cem) ( $n=17$ whole mouth/patient based randomisation). Bond failure. RCT.

\begin{tabular}{|c|c|}
\hline Mitchell 1992 & $\begin{array}{l}\text { Comparison of } 2 \text { chemical cured composites. } \\
\text { Compared chemical cured composites Direct and Right-On ( } n=24 \text { patients). Decalcification re- } \\
\text { ported. RCT. }\end{array}$ \\
\hline
\end{tabular}

Shamma 1999 Unable to use data. Statistical analysis unclear and possibly inappropriate. Survival curve was presented but no standard deviations. It was unclear whether curve was for first patient failure, or for failure of brackets at sites.

Compared 2 light cured composites (Reliance L3 and Light Bond) and light activated GIC (Fuji Ortho LC) ( $\mathrm{n}=30$ patients). Bond failure reported. RCT.

$\begin{array}{ll}\text { Sonis } 1989 & \text { Comparison of } 2 \text { light cured composites. } \\ & \text { Compared light cured composite fluoride release (Fluorever) and light cured composite with no } \\ & \text { fluoride (Aurafill) }(\mathrm{n}=22 \text { patients). Bond failure and decalcification reported. RCT. }\end{array}$

Unable to use data. Statistical analysis inappropriate: $\mathrm{Chi}^{2}$ analysis numbers of failures on a tooth rather than a patient basis.

Compared chemical cured composite (Right-On) and light cured composite (Transbond XT). Also compared bracket bases: DynalokAPC and uncoated brackets and mesh backed straight wire brackets ( $\mathrm{n}=40$ patients). Bond failure, bond failure/site reported. RCT.

\section{Trimpaneers 1996}

Unable to use data. Statistical analysis inappropriate: $\mathrm{Chi}^{2}$ analysis numbers of failures on a tooth rather than a patient basis.

Compared Orthon (light cured resin with fluoride) and Lee Orthodond (chemical cured resin with no fluoride) ( $n=50$ patients). Bond failure, bond failure/site reported. RCT.

\section{Turner 1993}

Comparison of 2 chemical cured composites.

Compared chemical cured composite no fluoride (Concise) and chemical cured composite with fluoride (De Trey Dentsply experimental) ( $n=42$ patients). Bond failure, decalcification, plaque score and gingival health reported. RCT. 


\begin{tabular}{ll}
\hline Study & Reason for exclusion \\
\hline Underwood 1989 & $\begin{array}{l}\text { Comparison of } 2 \text { chemical cured composites. } \\
\text { Compared fluoride releasing composite with a chemical cured composite (no fluoride) (Concise) ( } \mathrm{n} \\
=10 \text { patients). Bond failure, and decalcification on subsequently extracted premolars with polaris- } \\
\text { ing light microscope. CCT. }\end{array}$ \\
\hline Zacchrisson 1978 & $\begin{array}{l}\text { Comparison of } 2 \text { chemical cured composites. } \\
\text { Compared chemical cured composites (Endur and Concise). Also compared direct and indirect } \\
\text { bonding and mesh backed and perforated bracket bases }(\mathrm{n}=42 \text { patients). Bond failure, plaque, } \\
\text { gingival condition reported. RCT. }\end{array}$ \\
\hline
\end{tabular}

$\mathrm{CCT}=$ controlled clinical trial; $\mathrm{RCT}=$ randomised controlled trial.

\section{ADDITIONAL TABLES}

Table 1. Light cured composite versus chemical cured composite

\begin{tabular}{lllll}
\hline Study & Intervention & N children & $\begin{array}{l}\text { N brackets } \\
\text { placed }\end{array}$ & N failed (\%) \\
\hline O'Brien 1989 & Light cured (Mesh foil base) & 52 & 128 & $5(3.9)$ \\
\hline O'Brien 1989 & Chemical cured (Mesh foil base) & 52 & 123 & $6(4.9)$ \\
\hline O'Brien 1989 & Light cured (Micro-loc base) & 52 & 127 & $7(5.5)$ \\
\hline O'Brien 1989 & Chemical cured (Micro-loc base) & 52 & 107 & $8(7.5)$ \\
\hline
\end{tabular}

Table 2. Chemical cured composite versus conventional glass ionomer cement

\begin{tabular}{lllll}
\hline Study & Intervention & N children & N placed & N failed (\%) \\
\hline Norevall 1996 & Unite (mesh foil base) & 60 & 255 & $18(7)$ \\
\hline Norevall 1996 & Aquacem (mesh foil base) & 60 & 256 & $56(22)$ \\
\hline Norevall 1996 & Unite (cut groove base) & 60 & 238 & $54(23)$ \\
\hline Norevall 1996 & Aquacem (cut groove base) & 60 & 236 & $118(50)$ \\
\hline
\end{tabular}

Table 3. Chemical cured composite versus light cured compomer

\begin{tabular}{lllll}
\hline Study & Intervention & N of children & N brackets & N failed (\%) \\
\hline Millett 2000 & Right-on & 45 & 213 & $36(16.9)$ \\
\hline Millett 2000 & Dyract Ortho & 45 & 213 & $43(20.2)$ \\
\hline
\end{tabular}




\section{AP P E N D C E S}

\section{Appendix 1. Cochrane Oral Health's Trials Register search strategy}

1 ((resin* or cement $^{\star}$ or bond $^{\star}$ or compomer ${ }^{\star}$ or composite $^{\star}$ or "glass ionomer ${ }^{\star}$ " or adhesive $\left.{ }^{\star}\right)$ :ti,ab) AND (INREGISTER)

2 ((orthodontic* and (bracket* or brace* or bond $\left.\left.{ }^{\star}\right)\right):$ ti,ab) AND (INREGISTER)

3 (\#1 and \#2) AND (INREGISTER)

\section{Appendix 2. Cochrane Central Register of Controlled Clinical Trials (CENTRAL) search strategy}

\#1 [mh^"Orthodontic brackets"]

\#2 (orthodontic* and (brace* or bracket $\left.{ }^{\star}\right)$ )

\#3 (orthodontic* and bond*)

\#4 \{or \#1-\#3\}

\#5 [mh "Composite resins"]

\#6 [mh Compomers]

\#7 [mh^^"Resin cements"]

\#8 [mh "Dental bonding"]

\#9 (resin ${ }^{\star}$ or cement ${ }^{\star}$ or bond ${ }^{\star}$ or compomer ${ }^{\star}$ or composite* or "glass ionomer ${ }^{\star}$ " or adhesive $\left.{ }^{\star}\right):$ ti,ab

\#10 \{or \#5-\#9\}

$\# 11$ \#3 and \#10

\section{Appendix 3. MEDLINE Ovid search strategy}

1 ORTHODONTIC BRACKETS/

2 orthodontic\$ and (brace\$ or bracket\$)

3 orthodontic\$ and bond\$

4 OR/1-3

5 Explode COMPOSITE RESINS/

6 Explode COMPOMERS

7 RESIN CEMENTS/

8 Explode DENTAL BONDING/

9 (resin\$ or cement\$ or bond\$ or compomer\$ or composite\$ or glass ionomer $\$$ or adhesive\$)

10 OR/5-9

113 AND 10

The above subject search was linked to the Cochrane Highly Sensitive Search Strategy (CHSSS) for identifying randomised trials in MEDLINE: sensitivity maximising version (2008 revision) as referenced in Chapter 6.4.11.1 and detailed in box 6.4.c of theCochrane Handbook for Systematic Reviews of Interventions, Version 5.1.0 (updated March 2011) (Lefebvre 2011).

1. randomized controlled trial.pt.

2. controlled clinical trial.pt.

3. randomized.ab.

4. placebo.ab.

5. drug therapy.fs.

6. randomly.ab.

7. trial.ab.

8. groups.ab.

9. or/1-8

10. exp animals/ not humans.sh.

11.9 not 10

\section{Appendix 4. Embase Ovid search strategy}

1. Orthodontic bracket/

2. (orthodontic\$ and (brace\$ or bracket\$)).ti,ab.

3. (orthodontic\$ and bond\$).ti,ab.

4. or/1-3

5. $\exp \operatorname{Resin} /$

6. exp Compomer/

7. Resin cement/

8. exp Dental bonding/

9. (resin\$ or cement\$ or bond\$ or compomer\$ or composite\$ or "glass ionomer\$" or adhesive\$).ti,ab. 
10. or/5-9

11.3 and 10

The above subject search was linked to adapted version of the Cochrane Embase Project filter for identifying RCTs in Embase Ovid (see http://www.cochranelibrary.com/help/central-creation-details.html for information):

1. Randomized controlled trial/

2. Controlled clinical study/

3. Random\$.ti,ab.

4. randomization/

5. intermethod comparison/

6. placebo.ti,ab.

7. (compare or compared or comparison).ti.

8. ((evaluated or evaluate or evaluating or assessed or assess) and (compare or compared or comparing or comparison)).ab.

9. (open adj label).ti,ab.

10. ((double or single or doubly or singly) adj (blind or blinded or blindly)).ti,ab.

11. double blind procedure/

12. parallel group\$1.ti,ab.

13. (crossover or cross over).ti,ab.

14. ((assign\$ or match or matched or allocation) adj5 (alternate or group\$1 or intervention\$1 or patient $\$ 1$ or subject\$1 or participant

\$1)).ti,ab.

15. (assigned or allocated).ti,ab.

16. (controlled adj7 (study or design or trial)).ti,ab.

17. (volunteer or volunteers).ti,ab.

18. trial.ti.

19. or/1-18

20. (exp animal/ or animal.hw. or nonhuman/) not (exp human/ or human cell/ or (human or humans).ti.)

21. 19 not 20

\section{Appendix 5. US National Institutes of Health Ongoing Trials Register (ClinicalTrials.gov) and the WHO International} Clinical Trials Registry Platform search strategy

orthodontic and bracket and adhesive

orthodontic and brace and adhesive

WHAT'S NEW

\begin{tabular}{lll}
\hline Date & Event & Description \\
\hline 8 May 2018 & Review declared as stable & $\begin{array}{l}\text { This review will not be updated until a substantial body of evi- } \\
\text { dence on the topic becomes available. If trials are conducted and } \\
\text { found eligible for inclusion in the future, the review would then } \\
\text { be updated accordingly. }\end{array}$ \\
\hline
\end{tabular}

\section{HISTORY}

Protocol first published: Issue 3, 2000

Review first published: Issue 2, 2003

\begin{tabular}{lll}
\hline Date & Event & Description \\
\hline 6 March 2018 & $\begin{array}{l}\text { New citation required but conclusions } \\
\text { have not changed }\end{array}$ & $\begin{array}{l}\text { New search, no new studies identified. Only search methods sec- } \\
\text { tions updated. Minor edits. }\end{array}$ \\
\hline 6 March 2018 & New search has been performed & $\begin{array}{l}\text { An updated search of all databases was conducted 26 September } \\
\text { 2017. No additional studies were identified. }\end{array}$ \\
\hline
\end{tabular}




\begin{tabular}{lll}
\hline Date & Event & Description \\
\hline 15 September 2008 & Amended & Converted to new review format.
\end{tabular}

\section{CONTRIBUTIONSOF AUTHORS}

Nicky Mandall (NM), Declan Millett (DTM), Rye Mattick (CRM) and Joy Hickman (JH2) wrote the protocol and NM and Helen Worthington (HW) the review. NM co-ordinated the review and wrote the letters to authors. All authors independently and in duplicate assessed the eligibility of trials, extracted data and assessed the quality of the trials. HW and Tatiana Macfarlane (TM) assessed the appropriateness of the statistical analysis. DTM was not involved in the assessment of one of the included trials for which he is also an author.

\section{DECLARATIONS OF INTEREST}

Nicky A Mandall: none known.

Joy Hickman: none known.

Tatiana V Macfarlane: none known.

Rye CR Mattick: none known.

Declan T Millett: he was not involved in the assessment of one of the included trials for which he is also an author.

Helen V Worthington: none known. Helen Worthington is Co-ordinating Editor for Cochrane Oral Health.

\section{SOURCES OF SUPPORT}

\section{Internal sources}

- University Dental Hospital of Manchester, UK.

- Glasgow Dental Hospital and School, UK.

\section{External sources}

- National Institute for Health Research (NIHR), UK.

This project was supported by the NIHR, via Cochrane Infrastructure funding to Cochrane Oral Health. The views and opinions expressed herein are those of the review authors and do not necessarily reflect those of the Systematic Reviews Programme, the NIHR, the NHS or the Department of Health.

- Cochrane Oral Health Global Alliance, Other.

The production of Cochrane Oral Health reviews has been supported financially by our Global Alliance since 2011 (oralhealth.cochrane.org/partnerships-alliances). Contributors over the past year have been the American Association of Public Health Dentistry, USA; AS-Akademie, Germany; the British Association for the Study of Community Dentistry, UK; the British Society of Paediatric Dentistry, UK; the Canadian Dental Hygienists Association, Canada; the Centre for Dental Education and Research at All India Institute of Medical Sciences, India; the National Center for Dental Hygiene Research \& Practice, USA; New York University College of Dentistry, USA; NHS Education for Scotland, UK; and the Swiss Society for Endodontology, Switzerland.

\section{N O T E S}

This review will not be updated until a substantial body of evidence on the topic becomes available. If trials are conducted and found eligible for inclusion in the future, the review would then be updated accordingly.

\section{INDEX TERMS}

\section{Medical Subject Headings (MeSH)}

*Dental Bonding; *Dental Cements; *Orthodontic Brackets; Compomers; Decalcification, Pathologic; Glass lonomer Cements; Randomized Controlled Trials as Topic

\section{MeSH check words}

Humans 